\title{
The Role of the Endoplasmic Reticulum in Peroxisome Biogenesis
}

\author{
Lazar Dimitrov ${ }^{1,2}$, Sheung Kwan Lam ${ }^{1}$, and Randy Schekman ${ }^{1,2}$ \\ ${ }^{1}$ Department of Molecular and Cell Biology, University of California, Berkeley, California 94720 \\ ${ }^{2}$ Howard Hughes Medical Institute, University of California, Berkeley, California 94720 \\ Correspondence: schekman@berkeley.edu
}

Peroxisomes are essential cellular organelles involved in lipid metabolism. Patients affected by severe peroxisome biogenesis disorders rarely survive their first year. Genetic screens in several model organisms have identified more than 30 PEX genes that are required for the formation of functional peroxisomes. Despite significant work on the PEX genes, the biogenic origin of peroxisomes remains controversial. For at least two decades, the prevailing model postulated that peroxisomes propagate by growth and fission of preexisting peroxisomes. In this review, we focus on the recent evidence supporting a new, semiautonomous model of peroxisomal biogenesis. According to this model, peroxisomal membrane proteins (PMPs) traffic from the endoplasmic reticulum (ER) to the peroxisome by a vesicular budding, targeting, and fusion process while peroxisomal matrix proteins are imported into the organelle by an autonomous, posttranslational mechanism. We highlight the contradictory conclusions reached to answer the question of how PMPs are inserted into the ER. We then review what we know and what still remains to be elucidated about the mechanism of PMP exit from the ER and the contribution of preperoxisomal vesicles to mature peroxisomes. Finally, we discuss discrepancies in our understanding of de novo peroxisome biogenesis in wild-type cells. We anticipate that resolving these key issues will lead to a more complete picture of peroxisome biogenesis.

$T^{1}$ he separation of metabolic and biosynthetic functions within discrete organelles is a hallmark of eukaryotic cells. Peroxisomes are single-membrane-bound organelles whose most conserved function is the compartmentalization of $\beta$-oxidation of fatty acids and the breakdown of the hydrogen peroxide generated by this process. The importance of peroxisomes for normal human development is underscored by a spectrum of peroxisome biogenesis disorders (PBDs) (Kunau 1998; Brosius and Gärt- ner 2002; Steinberg et al. 2006). Patients affected by the most severe of the PBDs-Zellweger syndrome, lack functional peroxisomes, suffer from developmental delay, low muscle tone, hearing impairment, and rarely survive their first year (reviewed by Sacksteder and Gould 2000).

The search for genes defective in PBD patients has been greatly aided by genetic screens for peroxisome biogenesis (pex) mutants in several divergent yeasts (Erdmann et al. 1989;

Editors: Susan Ferro-Novick, Tom A. Rapoport, and Randy Schekman

Additional Perspectives on The Endoplasmic Reticulum available at www.cshperspectives.org

Copyright (C) 2013 Cold Spring Harbor Laboratory Press; all rights reserved; doi: 10.1101/cshperspect.a013243

Cite this article as Cold Spring Harb Perspect Biol 2013;5:a013243 
L. Dimitrov et al.

Gould et al. 1992; Liu et al. 1992; Tan et al. 1995). Yeast serves as an excellent model system because the process of peroxisome biogenesis is evolutionarily very well conserved. Thus, the majority of human genes defective in PBDs were discovered by searching for the human homologs of the PEX genes first cloned in yeast (Sacksteder and Gould 2000).

Despite decades of research on peroxisome biogenesis, the origin of the organelle remains controversial. Classic morphologic work pointed to an origin of peroxisomal membranes from the endoplasmic reticulum (ER) (Novikoff and Novikoff 1972). Subsequently, it was discovered that peroxisomal matrix proteins are translated on free ribosomes and imported posttranslationally directly from the cytosol (Goldman and Blobel 1978) (Fig. 1). These proteins contain two varieties of peroxisomal targeting signals (PTS1 or PTS2) that are necessary and sufficient for directing soluble proteins to the peroxisomal matrix (Gould et al. 1987; Swinkels et al. 1991). The analogy with mitochondrial and chloroplast protein import led to a shift in the scientific thinking toward a "growth and fission" model in which peroxisomes were considered autonomous organelles that derive from preexisting ones (Lazarow and Fujiki 1985) (Fig. 1). In their influential review, Lazarow and Fujiki's main argument against the ER origin of peroxisomes was that classical electron micrographs do not convincingly show direct lumenal connections between peroxisomes and the ER (Lazarow and Fujiki 1985). Nonetheless, peroxisomal content could flow from the ER by a vesicular budding, targeting, and fusion process that would not depend on lumenal continuity (Fig. 2).

Another reason why the origin of the peroxisomal membrane remains difficult to pin down is that peroxisomes or remnants thereof are not detectable in only two, pex19 and pex3, of the more than 30 pex mutants identified thus

\section{Peroxisomal matrix protein traffic}

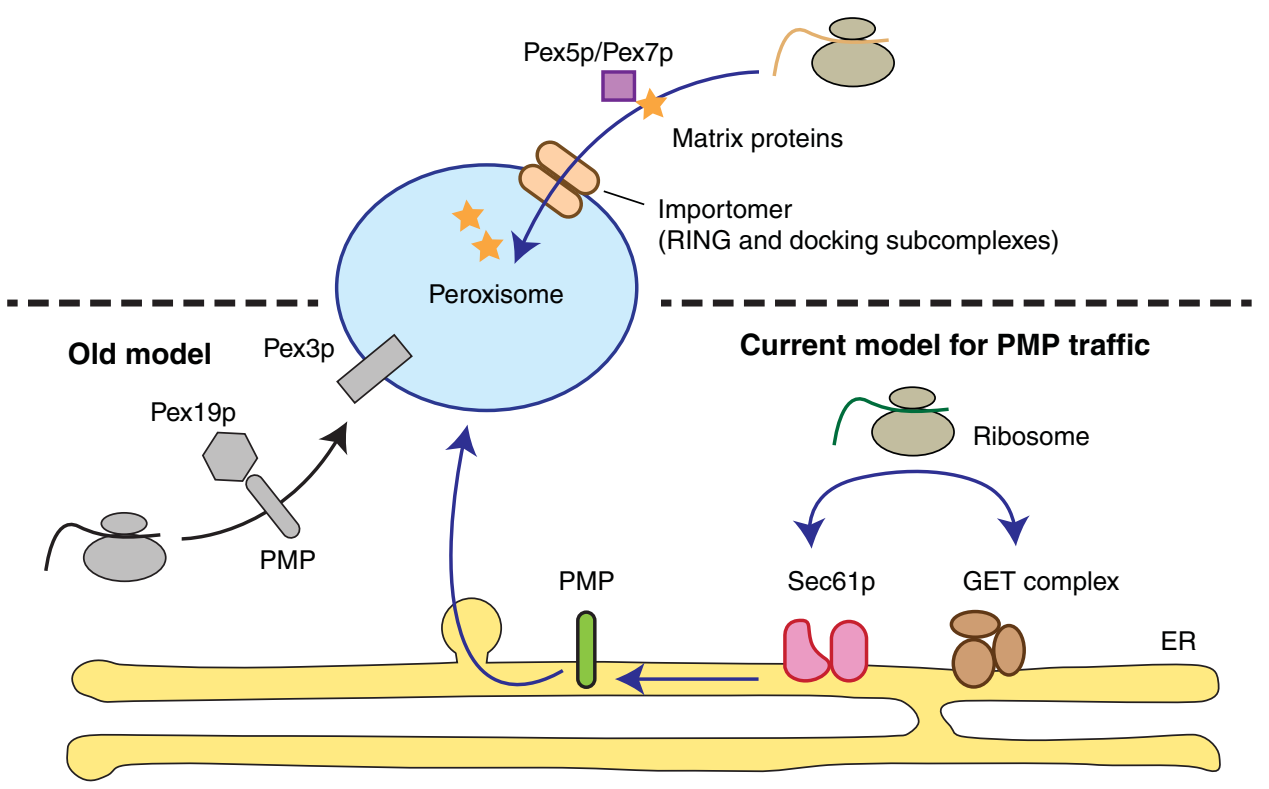

Figure 1. Protein traffic to the peroxisome. Under the old model (Lazarow and Fujiki 1985), peroxisomal membrane proteins (PMPs) target to the organelle after translation on cytosolic ribosomes. Recent evidence, however, argues that PMPs are first inserted into the endoplasmic reticulum (ER) via either the Sec61 translocon or the GET (Get1p/Get2p/Get3p) complex. Subsequently, the PMPs exit the ER to reach the peroxisome. There is consensus in the literature that peroxisomal matrix proteins target to the organelle after translation on cytosolic ribosomes. 
The ER and Peroxisome Biogenesis

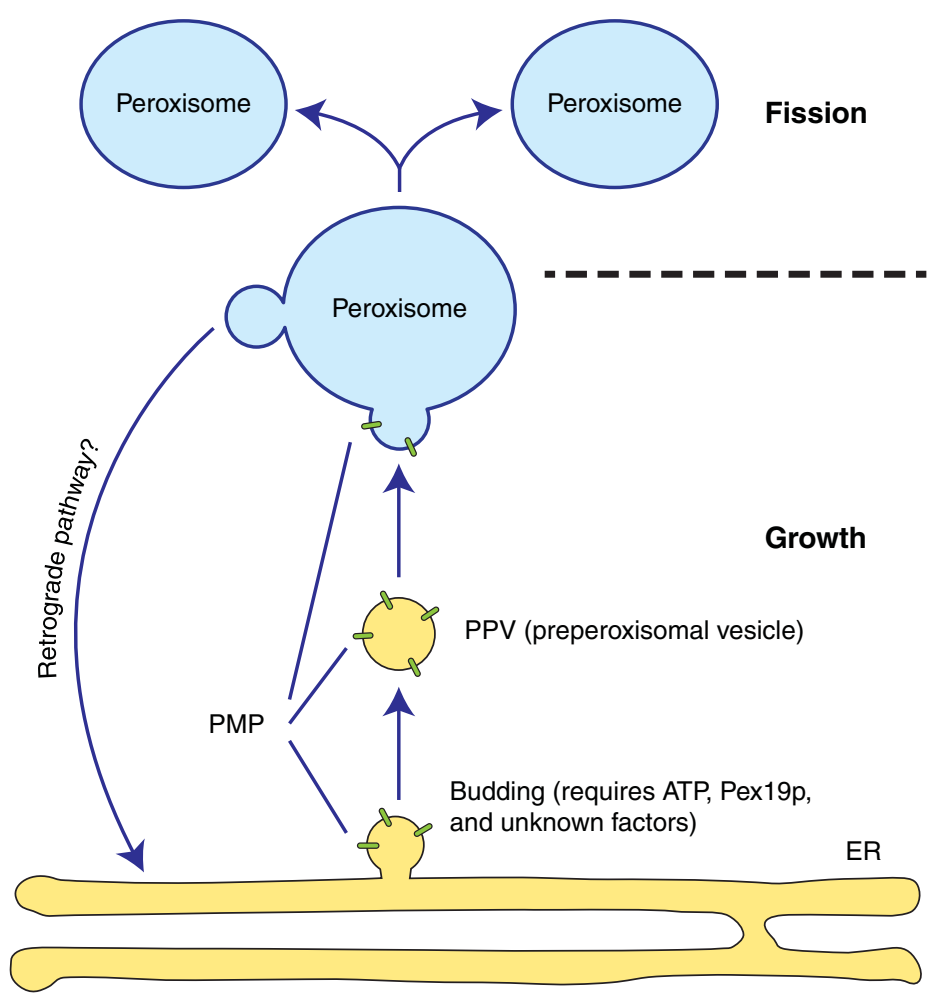

Figure 2. Contribution of the endoplasmic reticulum to peroxisome biogenesis. Peroxisomal membrane proteins (PMPs) exit the endoplasmic reticulum (ER) in preperoxisomal vesicles (PPVs), which target to and fuse with mature peroxisomes. Apart from Pex19p, the cytosolic factors required for PPV budding are unknown. PPVs contribute to peroxisomal growth by delivering new lipids and PMPs. Subsequent fission of mature peroxisomes maintains organelle numbers during each cell division. The existence of a retrograde trafficking pathway from peroxisomes to the ER is an open question. Moreover, the extent to which PPVs can fuse with each other to generate a new peroxisome in wild-type cells appears to differ between yeast and mammalian cells (Kim et al. 2006; Motley and Hettema 2007; van der Zand et al. 2012).

far in the yeast Saccharomyces cerevisiae (Höhfeld et al. 1991; Götte et al. 1998). In mammalian cells but not in yeast, an additional gene, $P E X 16$, is required for peroxisomal membrane biogenesis (Honsho et al. 1998; South and Gould 1999). The precise molecular functions of the Pex19, Pex3, and Pex16 proteins are not known. Pex 19p is a predominantly cytosolic protein that binds to the membrane protein targeting signal (mPTS) motifs of peroxisomal membrane proteins (PMPs) (Jones et al. 2004; Rottensteiner et al. 2004) (Fig. 1). Within the context of the "growth and fission" model of peroxisome biogenesis, Pex19p was thought to facilitate PMP insertion directly into the perox- isomal membrane as either a PMP receptor or chaperone (Hettema et al. 2000; Snyder et al. 2000; Jones et al. 2004). Pex3p is an integral membrane protein that binds to Pex19p (Götte et al. 1998) and is proposed to function as a Pex19p docking factor in the direct import of PMPs into the peroxisome (Fang et al. 2004) (Fig. 1). In mammalian cells, PEX16 is proposed to function as a receptor for Pex3p-Pex19p complexes at the peroxisomal membrane (Matsuzaki and Fujiki 2008).

In this review we focus on the recent literature that supports the resurgent model of peroxisome biogenesis from the ER. For a more detailed historical account of the vicissitudes 
L. Dimitrov et al.

in models about peroxisome biogenesis, including less recent findings suggesting an ER origin of the organelle, we refer the reader to excellent reviews elsewhere (Kunau and Erdmann 1998; Titorenko and Rachubinski 1998; Tabak et al. 2008). The import of peroxisomal matrix proteins and the inheritance of the organelle have been reviewed elsewhere as well (Fagarasanu et al. 2010; Schliebs et al. 2010).

\section{THE ER ORIGIN OF PEROXISOMES}

The "growth and fission" model prevailed for the two decades since Lazarow and Fujiki's review (Lazarow and Fujiki 1985) despite accumulating evidence that peroxisomes can arise de novo. In mutants that lack detectable peroxisomes, the organelle is regenerated on reintroduction of the wild-type version of the mutated gene (reviewed by Subramani 1998). Such de novo biogenesis has not been observed for autonomous organelles such as mitochondria and chloroplasts.

The ER origin of peroxisomes received its most direct support in a paper from the Tabak group (Hoepfner et al. 2005). The authors developed a pulse-chase assay in which PEX3-YFP is expressed from the galactose-inducible promoter as the sole Pex3p source in cells otherwise devoid of peroxisomes. A 30-min galactose pulse followed by a glucose chase results in the one-time expression of Pex3p-YFP to levels comparable to those achieved from the endogenous PEX3 promoter. These physiological levels of Pex3p are sufficient to regenerate importcompetent peroxisomes. Moreover, time-lapse microscopy reveals that Pex3p-YFP first concentrates into foci on the ER membrane and then migrates in a Pex19p-dependent manner to peroxisomes. This evidence argues strongly that the intracellular traffic of at least one PMP, Pex $3 p$, proceeds from the ER to peroxisomes. Two independent groups came to similar conclusions about the trafficking of Pex3p to peroxisomes (Kragt et al. 2005; Tam et al. 2005). In 2010, the Tabak group extended their fluorescence pulse-chase analysis to many other PMPs and concluded that most, if not all, $S$. cerevisiae PMPs traffic to peroxisomes via the ER in a
Pex3p- and Pex19p-dependent manner (van der Zand et al. 2010).

Evidence in favor of the ER to peroxisome pathway in mammalian cells focused on the Pex16 protein (Kim et al. 2006). The authors found that Pex16p localizes to peroxisomes in COS-7 cells at low expression levels. However, on Pex16p overexpression, the predominant localization of the protein is to the ER. Presumably, the machinery for Pex16p traffic from the ER to peroxisomes is saturated at higher expression levels. Using a photoactivatable version of GFP to tag PEX16, the authors show convincingly that the ER localization of Pex16p represents an intermediate in the delivery of Pex16p to peroxisomes. This delivery is dependent on the mPTS of Pex16p located in the protein's amino terminus. Moreover, the authors append to Pex16p an amino-terminal type I signal anchor sequence to force Pex16p to be cotranslationally inserted into the ER. In this case, the protein still targets to peroxisomes and complements PEX16-deficient human cells.

\section{HOW ARE PEROXISOMAL MEMBRANE PROTEINS INSERTED INTO THE ER?}

The majority of proteins targeted to the ER coor posttranslationally are substrates of the Sec61 translocon (Osborne et al. 2005). If PMPs traffic to peroxisomes via the ER, then what is the mechanism for their insertion into the ER membrane? The literature on this subject has been surprisingly controversial as well. The first published study on the requirement of the Sec61 translocon for peroxisome biogenesis was a negative result but appeared during the reign of the "growth and fission" model (South et al. 2001). The authors used a cold-sensitive sec61-11 allele that blocks protein translocation into the ER only $15 \mathrm{~min}$ after a shift to $17^{\circ} \mathrm{C}$. They followed de novo peroxisome biogenesis by expressing Pex3p under the galactose-inducible promoter. However, because they did not perform a glucose chase, a caveat to their study is that Pex $3 \mathrm{p}$ is overexpressed. Unlike the more recent Pex $3 p$ pulse-chase experiments (Hoepfner et al. 2005; van der Zand et al. 2010; Thoms et al. 2012), South et al. induced Pex3p expression for about 
$20 \mathrm{~h}$ before they saw import-competent peroxisomes in about $30 \%$ of wild-type cells. They attributed this long period of peroxisome formation to the inhibitory effects of Pex3p overexpression. Despite these shortcomings, de novo peroxisome biogenesis occurred at the same rate and to the same extent in wild-type and sec6111 cells at the restrictive temperature (South et al. 2001).

A much more recent report revisited the requirement of the Sec61 translocon for peroxisome biogenesis and came to exactly the opposite conclusion (Thoms et al. 2012). The experimental setup, however, differs in two key aspects. First, the authors used a different conditional allele-sec61-2, which is temperature sensitive but unfortunately phenotypic for translocation into the ER even at the permissive temperature, raising the possibility that the strain may have accumulated second-site mutations. Second, the Pex3p expression level is more physiologically relevant because Pex3p is induced in galactose for only $45 \mathrm{~min}$ and subsequently chased with growth on glucose. The authors follow peroxisome regeneration for the first $4 \mathrm{~h}$ after galactose induction. At these physiological levels of Pex $3 p$ reexpression, about $80 \%$ of wild-type cells regenerate peroxisomes. In contrast, less than $5 \%$ of sec $61-2$ cells, grown at the permissive temperature, regenerate peroxisomes in the same time window. Despite this defect in de novo peroxisome biogenesis, however, at steady state sec61-2 cells grown at the permissive temperature contain similar numbers of import-competent peroxisomes as wildtype cells. This result suggests that the sec61-2 allele does not block but instead delays de novo peroxisome biogenesis.

Because the experimental setups of these two studies differ in several aspects, it is difficult to determine which one is responsible for the drastic difference in their conclusions. Additional experiments, which use several SEC61 alleles at their restrictive temperatures in the context of the more physiologically relevant pulse-chase assay, should resolve the controversy about the requirement of the Sec61 translocon in peroxisomes biogenesis. In the meantime, the results from a third independent study are consistent with a requirement for the Sec61 translocon in peroxisome biogenesis (van der Zand et al. 2010). These authors drove the expression of Sec62p and Sec63p from the methionine-repressible MET3 promoter. Cells with these alleles were grown in methionine-replete medium for $7 \mathrm{~h}$ to achieve partial depletion of Sec62p and Sec63p but not Sec61p. Microscopic analysis revealed the accumulation of cytosolic Pex13p-YFP even by $6 \mathrm{~h}$ of promoter repression. These results were confirmed biochemically by cellular fractionation of pex $3 \Delta$ cells to avoid the problem of leaky peroxisomes. Before SEC62 and SEC63 repression, Pex13p and Pex14p were exclusively found in the membrane fraction. Seven hours after the simultaneous repression of Sec62p and Sec63p, the three PMPs were also detectable in the cytosolic fraction. Thus, when we take all the evidence into account, the scales are tipping toward the view that the Sec61 translocon is required for PMP insertion into the ER (Fig. 1).

In contrast to the conflicting results about the Sec61 translocon, there is consensus in the literature about the trafficking of the only tailanchored PMP, Pex15p. Tail-anchored (TA) proteins targeted to the ER are recognized in the cytosol by Get3p and the Get3p-TA complex is recruited to the ER membrane by the heteromeric Get1p/Get2p receptor (Schuldiner et al. 2008) (Fig. 1). In their seminal report on the discovery of the GET complex, the authors showed that Get3p physically interacts with Pex15p in a yeast two-hybrid assay (Schuldiner et al. 2008). This interaction depends on the carboxy-terminal transmembrane domain of Pex15p. Moreover, in get $1 \Delta$ or get $2 \Delta$ mutant cells, Pex15p initially forms cytosolic aggregates. Extended overexpression leads to Pex15p mislocalization to mitochondria. The lag period to mitochondrial mislocalization of Pex15p is dramatically shortened in get $3 \Delta$ cells. In a later report, the Tabak group performed a fluorescent pulse-chase experiment to follow the traffic of YFP-Pex15p (van der Zand et al. 2010). They also found that Pex15p traffic is impaired in get $3 \Delta$ mutant cells. Thus, the GET complex is required for targeting Pex15p to the peroxisome via the ER. 
L. Dimitrov et al.

\section{HOW DO PEROXISOMAL MEMBRANE PROTEINS LEAVE THE ER?}

The observation that newly made Pex3p-GFP migrates from ER foci to peroxisomes (Hoepfner et al. 2005) raises the intriguing possibility that PMPs leave the ER in membrane-bound vesicles. Using S. cerevisiae as a model system, our laboratory was the first to establish a cellfree budding reaction that reproduces the formation of preperoxisomal vesicles (PPVs) (Fig. 2) responsible for the transit of at least two PMPs-Pex3p and Pex15p, from the ER (Lam et al. 2010). When cytosol from wild-type cells is incubated with microsomal membranes from pex19s cells, which lack detectable peroxisomes, Pex3p and Pex15p are incorporated into a slowly sedimenting vesicle fraction. This process is ATP-dependent but independent of the small GTPase Sar1, which initiates the assembly of the COPII machinery responsible for secretory cargo packaging at the ER (Box 1) (Zanetti et al. 2012). The PPV budding reaction also requires Pex19p in the cytosol fraction but recombinant Pex19p is not sufficient. Thus, PPV production requires additional cytosolic factors, which are likely to be proteins because the cytosolic activity is heat- and trypsin-sensitive (Fig. 2). However, other known Pex proteins with cytosolic localization (Pexlp, Pex5p, Pex6p, and Pex7p) are not required in the cytosol for PPV budding. An independent study from the Subramani group in permeabilized Pichia pastoris cells reached remarkably similar conclusions despite the different model organism, source of donor membranes, PMPs investigated and reaction conditions (Agrawal et al.
2011). They also found that Pex11p-containing vesicles bud even when pex3 $\Delta$ permeabilized cells are used as donor membranes. The resultant vesicles, however, lack most other PMPs tested.

If PMPs bud from the ER in membranebound vesicles, then the next pressing question concerns the identity of the other cytosolic proteins responsible for PPV formation (Fig. 2). The in vitro budding reactions rule out the involvement of the canonical COPII coat (Box 1). Moreover, two independent studies in human cell lines concluded that the COPII and COPI coats (Box 1) are not required for peroxisomal biogenesis (South et al. 2000; Voorn-Brouwer et al. 2001). Both studies used dominant negative alleles of Sar1p and brefeldin A (BFA) treatment (Box 1) to rule out the requirement of the canonical COPII and COPI coats, respectively, for PMP targeting to peroxisomes. On the other hand, a study in the yeast Hansenula polymorpha found that BFA treatment leads to the reversible accumulation of newly synthesized PMPs and peroxisomal matrix proteins in the ER, but not to a complete block in peroxisome biogenesis (Salomons et al. 1997). Thus, there could be some species-specific differences in the involvement of COPI in peroxisome biogenesis. In this regard, COPI has also been proposed to play a role in peroxisome fission because purified rat liver peroxisomes recruit COPI in GTP $\gamma \mathrm{S}$-dependent manner and a Chinese hamster ovary cell line with a temperature-sensitive allele of $\varepsilon$-COP develops elongated, tubular peroxisomes at the restrictive temperature (Passreiter et al. 1998). In summary, the identity of the additional soluble proteins and the putative

\section{BOX 1. DEFINITIONS}

COPII Coat protein complex II responsible for the formation of vesicles involved in anterograde cargo transport from the endoplasmic reticulum (ER) to the Golgi apparatus.

COPI Coat protein complex I responsible for the formation of vesicles involved in retrograde transport of resident proteins among Golgi cisternae and in the retrieval of ER proteins from the cis-Golgi cisterna.

Sar1 A small Arf-like GTPase that initiates the assembly of the COPII coat.

Brefeldin A Inhibitor of a GTP exchange factor responsible for the activation of Arf1, a small GTPase

(BFA) that initiates the assembly of the COPI coat. 
The ER and Peroxisome Biogenesis

ATPase required in the PPV budding reaction remain unknown. These proteins may have been missed in prior genetic screens because of redundancy or their essential function in other cellular processes. The discovery and characterization of these additional cytosolic factors remains an active area of research.

In mammalian cells, a clue to the identity of the machinery responsible for Pex16p exit from the ER comes from a recent study that implicates the Sec16B isoform in peroxisome biogenesis (Yonekawa et al. 2011). Knock-down of Sec16B but not Sec16A leads to ER localization for Pex16p. Moreover, a fluorescent pulsechase analysis revealed that Sec16B is required for the delivery of Pex16p from the ER to peroxisomes. Both Sec16 isoforms are involved in ER exit site formation (Bhattacharyya and Glick 2007). Truncated Sec16B mutants, however, showed that ER exit site localization is separable from the protein's role in Pex16p traffic. S. cerevisiae has a single SEC16 gene that is the ortholog of the longer Sec16A mammalian isoform. Thus, it is unclear if yeast contains a functional ortholog of the SEC16B gene. Identifying proteins that bind specifically to Sec16B may reveal other players in mammalian peroxisome biogenesis from the ER.

We finish this section by mentioning two additional outstanding questions related to vesicular traffic between the ER and peroxisomes. First, how are PMPs sorted away from ER-resident and classical secretory pathway proteins during their traffic to the peroxisome? The current literature provides no clues to answer this question. Thus, genetic screens for mutants in which an ER-resident or secretory protein mislocalizes to peroxisomes may be necessary. Second, is there a retrograde pathway from peroxisomes back to the ER, given the precedent for such a pathway from the Golgi apparatus to the ER (Fig. 2)? One proposal for a retrograde pathway from peroxisomes to the ER mediated by COPI-coated vesicles is based on results that have not been followed up since 1998 (Passreiter et al. 1998; Titorenko and Rachubinski 1998). Testing this hypothesis as well as the existence of a retrograde pathway should be another focus of future research.

\section{HOW DO PREPEROXISOMAL VESICLES CONTRIBUTE TO MATURE PEROXISOMES?}

With the exception of Salomons et al.'s work on Hansenula polymorpha cells treated with BFA (Salomons et al. 1997), we are not aware of any other report in which soluble peroxisomal matrix enzymes are localized to the ER. Thus, a functional peroxisomal importomer-the translocon responsible for import of soluble PTS1or PTS2-containing proteins into the peroxisomal matrix, must not assemble in the ER membrane. The importomer consists of two halves - the docking subcomplex, which contains the PMPs Pex13p and Pex14p, and the RING subcomplex, which contains the PMPs Pex2p, Pex10p, and Pex12p (Agne et al. 2003) (Fig. 1). Given our thinking that all PMPs traffic to the peroxisome via the ER, how is importomer assembly prevented in the ER membrane?

Progress toward answering this question comes from the recent demonstration that mature, import-competent peroxisomes are formed by the heterotypic fusion of at least two molecularly distinct PPVs (van der Zand et al. 2012). The authors used a split-GFP complementation assay (Hu et al. 2002) to follow the generation of newly synthesized importomer complexes. The nonfluorescent amino- and carboxy-terminal halves of Venus fluorescent protein (VFP) were each fused to different PMPs in haploid cells that were subsequently mated. Fluorescence complementation in the resulting diploid zygote indicates physical interaction between the two PMPs. When wild-type haploid cells were mated, fluorescence complementation was achieved between tagged members within the docking subcomplex (Pex13p-Pex14p), within the RING subcomplex (Pex2p-Pex10p), and across the two subcomplexes (Pex2p-Pex14p and Pex10p-Pex13p). Remarkably, when pex3s or pex $19 \Delta$ haploid cells were mated, fluorescence complementation was seen only between proteins within a subcomplex (Pex13p-Pex14p and Pex $2 p-P e x 10 p)$ but not for proteins across the subcomplexes (Pex2p-Pex14p and Pex10pPex13p). The authors argue that the reconstituted docking and RING subcomplexes are in the ER membrane based on their prior pulse- 
L. Dimitrov et al.

chase studies (van der Zand et al. 2010). However, direct evidence for subcomplex formation in the ER membrane requires the demonstration that the reconstituted VFP signal colocalizes with an ER fluorescent marker of different color. Despite this shortcoming, the evidence suggests that the docking and RING subcomplexes can assemble in the ER membrane without reconstituting a functional importomer in pex3s or pex $19 \Delta$ cells.

Another remarkable finding is that a similar lack of VFP complementation across subcomplex members occurs in mating pex $1 \Delta$ or pex $6 \Delta$ cells. Prior studies in Yarrowia lipolytica implicate the NSF-like $\left(\mathrm{AAA}^{+}\right)$proteins Pexlp and Pex6 $\mathrm{p}$ in the heterotypic fusion of purified PPVs leading to the proposal that different PPVs fuse to form mature peroxisomes (Titorenko and Rachubinski 2000; Titorenko et al. 2000). This model receives further support in the more recent study (van der Zand et al. 2012) in which the authors provide fluorescence localization evidence that the docking and RING subcomplexes are kept in distinct PPVs. Compartments harboring the subcomplexes have to fuse to reconstitute a functional importomer and generate new mature peroxisomes. Heterotypic fusion between PPVs and preexisting peroxisomes and between mature peroxisomes was not detected (van der Zand et al. 2012).

Whereas the intriguing finding that the docking and RING subcomplexes leave the ER in molecularly distinct PPVs is a major step toward understanding why peroxisomal matrix proteins are not observed in the ER lumen, the original question remains: What is the mechanism for preventing importomer reconstitution in the ER membrane? One possibility is that the docking and RING subcomplexes need to pair in a trans rather than cis orientation to reconstitute a functional importomer by analogy to the functional association of SNARE proteins in trans to promote membrane fusion. An alternative possibility is that an inhibitory factor localized to the ER membrane prevents importomer reconstitution. Yet another possibility is that different ER subdomains are required for the budding of the distinct PPVs. In this case, one must ask how the different ER subdomains are segregated, how
PMPs are sorted into the different PPVs, and which SNARE proteins, if any, specify the heterotypic fusion event.

\section{DOES DE NOVO PEROXISOME BIOGENESIS OCCUR IN WILD-TYPE CELLS?}

The latest finding that PPVs fuse to form new peroxisomes that add to the preexisting pool of organelles (van der Zand et al. 2012) is hard to reconcile with the prior evidence that de novo peroxisome biogenesis occurs only in cells devoid of peroxisomes (Motley and Hettema 2007). Both studies were conducted in S. cerevisiae but use slightly different experimental setups that are described in detail in Table 1. The earlier report convincingly showed that the majority of peroxisomes in wild-type $S$. cerevisiae cells are generated from preexisting peroxisomes (Motley and Hettema 2007), although a low level of de novo biogenesis may have escaped their detection. Moreover, they show that Pex3p-GFP traffics from the ER to preexisting peroxisomes in newly formed zygotes heterozygous for pex19s (Table 1, fourth column). This result contradicts the finding that Pex $3 p$ is on both types of PPVs, which do not fuse with preexisting peroxisomes but instead fuse to form new peroxisomes (van der Zand et al. 2012). One possibility for these discrepant results is that the latest study follows new peroxisome formation, which is assayed by reconstitution of the split-VFP signal, every $24 \mathrm{~h}$ for $72 \mathrm{~h}$. This time frame is much longer than the five hours necessary for de novo peroxisome biogenesis in cells devoid of peroxisomes in all prior pulse-chase studies from the same group (Hoepfner et al. 2005; van der Zand et al. 2010).

In contrast to $S$. cerevisiae, mammalian cells appear to prefer de novo formation of peroxisomes (Kim et al. 2006). The authors develop an assay based on a photoactivatable GFP-PTS1 fusion that allows them to distinguish between preexisting and newly generated peroxisomes. In their assay, de novo peroxisome biogenesis contributes the majority of new cellular peroxisomes (73\%), while fission of preexisting peroxisomes accounts for the remainder. Thus, it is possible that there are species-specific differ- 
The ER and Peroxisome Biogenesis

Table 1. Summary of experiments assessing the contribution of de novo peroxisome biogenesis in wild-type cells

\begin{tabular}{|c|c|c|c|c|}
\hline & \multicolumn{4}{|c|}{ References } \\
\hline & $\begin{array}{c}\text { (Motley and } \\
\text { Hettema 2007) }\end{array}$ & $\begin{array}{c}\text { (Motley and } \\
\text { Hettema 2007) }\end{array}$ & $\begin{array}{c}\text { (Motley and } \\
\text { Hettema 2007) }\end{array}$ & $\begin{array}{l}\text { (van der Zand } \\
\text { et al. 2012) }\end{array}$ \\
\hline Figure & $4 \mathrm{~B}$ & $4 \mathrm{C}$ & $5 B$ & $6 \mathrm{~B}$ \\
\hline $\begin{array}{l}\text { Use of mating } \\
\text { assay? }\end{array}$ & No & Yes & Yes & Yes \\
\hline Strain genotype & Wild type (WT) & $\mathrm{WT} \times \operatorname{pex} 3 \Delta$ & $\mathrm{WT} \times \operatorname{pex} 19 \Delta$ & $\mathrm{WT} \times \mathrm{WT}$ \\
\hline $\begin{array}{l}\text { Label for } \\
\text { preexisting } \\
\text { peroxisomes }\end{array}$ & $\begin{array}{l}3 \mathrm{~h} \text { galactose pulse } \\
\text { of GFP-PTS1 and } \\
2 \mathrm{~h} \text { glucose chase }\end{array}$ & $\begin{array}{l}3 \mathrm{~h} \text { galactose pulse of } \\
\text { GFP-PTS1 and } 5 \mathrm{~h} \\
\text { glucose chase in } \\
\text { WT mating partner }\end{array}$ & $\begin{array}{c}3 \text { h galactose pulse of } \\
\text { HcRed-PTS1 and } 2 \\
\text { h glucose chase in } \\
\text { WT mating partner }\end{array}$ & $\begin{array}{r}1.5 \text { h galactose pulse } \\
\text { of CFP-PTS1 and } \\
3 \text { h glucose chase }\end{array}$ \\
\hline $\begin{array}{l}\text { Label for new } \\
\text { peroxisomes }\end{array}$ & $\begin{array}{l}\text { Constitutive HcRed- } \\
\text { PTS1 in the same } \\
\text { strain }\end{array}$ & $\begin{array}{l}\text { HcRed-PTS1 in } \\
\text { pex } 3 \Delta \text { mating } \\
\text { partner }\end{array}$ & $\begin{array}{l}3 \mathrm{~h} \text { galactose pulse of } \\
\text { Pex } 3 \mathrm{p}-\mathrm{GFP} \text { and } 2 \mathrm{~h} \\
\text { glucose chase in } \\
\text { pex } 19 \Delta \text { mating } \\
\text { partner }\end{array}$ & $\begin{array}{l}\text { Reconstitution of } \\
\text { split-VFP signal } \\
\text { from interacting } \\
\text { PMPs }\end{array}$ \\
\hline $\begin{array}{l}\text { Time allowed } \\
\text { for de novo } \\
\text { biogenesis }\end{array}$ & $\begin{array}{l}6-8 \mathrm{~h} \text { in glucose } \\
\text { beyond the } 2 \mathrm{~h} \\
\text { chase }\end{array}$ & $5 \mathrm{~h}$ of glucose chase & $\begin{array}{l}2 \mathrm{~h} \text { of glucose chase } \\
\text { and } 2 \mathrm{~h} \text { after } \\
\text { mating }\end{array}$ & $\begin{array}{l}\text { Up to } 72 \mathrm{~h} \text {; figure } \\
\text { shows } 48 \mathrm{~h} \text { time } \\
\text { point }\end{array}$ \\
\hline Results & $\begin{array}{l}\text { No red-only } \\
\text { peroxisomes } \\
\text { detected }\end{array}$ & $\begin{array}{l}\text { No red-only } \\
\text { peroxisomes } \\
\text { detected }\end{array}$ & $\begin{array}{l}\text { Most of the punctate } \\
\text { Pex3p-GFP signal } \\
\text { co-localizes with } \\
\text { the red } \\
\text { peroxisomes }\end{array}$ & $\begin{array}{l}\text { Reconstituted split- } \\
\text { VFP signal does } \\
\text { not localize with } \\
\text { CFP-PTS1 signal }\end{array}$ \\
\hline Conclusions & $\begin{array}{l}\text { No peroxisomes } \\
\text { form de novo in } \\
\text { WT cells }\end{array}$ & $\begin{array}{l}\text { No peroxisomes form } \\
\text { de novo in WT } \times \\
\text { pex } 3 \Delta \\
\text { heterozygous } \\
\text { diploid cells }\end{array}$ & $\begin{array}{l}\text { ER-localized Pex3p- } \\
\text { GFP can be } \\
\text { transported to } \\
\text { preexisting } \\
\text { peroxisomes }\end{array}$ & $\begin{array}{l}\text { PPVs fuse and } \\
\text { mature to new } \\
\text { peroxisomes }\end{array}$ \\
\hline
\end{tabular}

ences in the regulation of the mix between de novo biogenesis and fission of peroxisomes in wild-type cells. Yeast appears to have dialed the rheostat so that fission of preexisting organelles dominates peroxisome maintenance at least under the growth conditions tested (Motley and Hettema 2007). Mammalian cells, on the other hand, appear to favor de novo peroxisome formation from the ER.

\section{CONCLUDING REMARKS}

We conclude that a model of peroxisome biogenesis, consistent with most of the existing data, calls for a semiautonomous origin of the organelle. In this model, peroxisomal membrane proteins are delivered by vesicular traffic from the ER and matrix proteins are translocated posttranslationally directly from the cytoplasm (Figs. 1 and 2). This model is also one of "growth and fission" (Fig. 2). However, the "growth" component has a dual origin-an endomembrane (PMPs and membrane lipids) and an autonomous one (peroxisomal matrix proteins). This model is surprisingly similar to the one discussed by Günter Blobel as far back as 1978 (Goldman and Blobel 1978). Given the pendulum swings in scientific opinion between an endomembrane versus autonomous origin of the peroxisome, it seems possible that the final model could change again.

We now briefly draw attention to some evidence in the literature that is hard to reconcile with the ER origin of peroxisomal membrane 
L. Dimitrov et al.

proteins. First, PMPs accumulate in mitochondria in fibroblasts from PBD patients with PEX3, PEX19, or PEX16 mutations (Sacksteder et al. 2000; South et al. 2000). Moreover, de novo peroxisome biogenesis can occur in $S$. cerevisiae when the sole copy of Pex $3 p$ is targeted to the mitochondrial outer membrane (Rucktäschel et al. 2010). Is there a mitochondria-to-peroxisome pathway or are these observations an artifact of protein overexpression or other off-pathway effects? A mitochondriato-peroxisome pathway has been suggested by studies in mammalian cells (Neuspiel et al. 2008; Braschi et al. 2010). Second, how do we reconcile the ER-to-peroxisome pathway with the old reports of in vitro PMP import directly into purified peroxisomes (Diestelkötter and Just 1993; Imanaka et al. 1996). Are those results plagued by the fragility of isolated peroxisomes (reviewed by Tabak et al. 2008), by contamination from other organelles or is there an alternative cytosol-to-peroxisome pathway? If PMPs can traffic directly to peroxisomes and there is no need to invoke a vesicular carrier for lipid delivery from the ER to the peroxisome (Raychaudhuri and Prinz 2008) then how do we reenvision the role of PPVs? Every field has its "dirty little secrets" (Yewdell 2005) and ours is no exception. Therefore, much remains to be clarified before a consistent and unified model of peroxisome biogenesis can be advanced.

\section{ACKNOWLEDGMENTS}

We apologize to the authors whose work could not be incorporated in this review because of space limitations. We thank Jennie Dorman for critical reading of the manuscript and discussions. L.D. is supported as a research associate by the Howard Hughes Medical Institute. S.K.L. is a Human Frontier Science Program postdoctoral fellow. R.S. is a Senior Fellow of the UC Berkeley Miller Institute and is supported as an Investigator of the Howard Hughes Medical Institute.

\section{REFERENCES}

Agne B, Meindl NM, Niederhoff K, Einwächter H, Rehling P, Sickmann A, Meyer HE, Girzalsky W, Kunau WH. 2003.
Pex8p: An intraperoxisomal organizer of the peroxisomal import machinery. Mol Cell 11: 635-646.

Agrawal G, Joshi S, Subramani S. 2011. Cell-free sorting of peroxisomal membrane proteins from the endoplasmic reticulum. Proc Natl Acad Sci 108: 9113-9118.

Bhattacharyya D, Glick BS. 2007. Two mammalian Sec16 homologues have nonredundant functions in endoplasmic reticulum (ER) export and transitional ER organization. Mol Biol Cell 18: 839-849.

Braschi E, Goyon V, Zunino R, Mohanty A, Xu L, McBride HM. 2010. Vps35 mediates vesicle transport between the mitochondria and peroxisomes. Curr Biol 20: $1310-1315$.

Brosius U, Gärtner J. 2002. Cellular and molecular aspects of Zellweger syndrome and other peroxisome biogenesis disorders. Cell Mol Life Sci 59: 1058-1069.

Diestelkötter P, Just WW. 1993. In vitro insertion of the 22$\mathrm{kD}$ peroxisomal membrane protein into isolated rat liver peroxisomes. J Cell Biol 123: 1717-1725.

Erdmann R, Veenhuis M, Mertens D, Kunau WH. 1989. Isolation of peroxisome-deficient mutants of Saccharomyces cerevisiae. Proc Natl Acad Sci 86: 5419-5423.

Fagarasanu A, Mast FD, Knoblach B, Rachubinski RA. 2010. Molecular mechanisms of organelle inheritance: Lessons from peroxisomes in yeast. Nat Rev Mol Cell Biol 11: 644-654.

Fang Y, Morrell JC, Jones JM, Gould SJ. 2004. PEX3 functions as a PEX19 docking factor in the import of class I peroxisomal membrane proteins. J Cell Biol 164: 863875.

Goldman BM, Blobel G. 1978. Biogenesis of peroxisomes: Intracellular site of synthesis of catalase and uricase. Proc Natl Acad Sci 75: 5066-5070.

Götte K, Girzalsky W, Linkert M, Baumgart E, Kammerer S, Kunau WH, Erdmann R. 1998. Pex19p, a farnesylated protein essential for peroxisome biogenesis. Mol Cell Biol 18: 616-628.

Gould SG, Keller GA, Subramani S. 1987. Identification of a peroxisomal targeting signal at the carboxy terminus of firefly luciferase. J Cell Biol 105: 2923-2931.

Gould SJ, McCollum D, Spong AP, Heyman JA, Subramani S. 1992. Development of the yeast Pichia pastoris as a model organism for a genetic and molecular analysis of peroxisome assembly. Yeast 8: 613-628.

Hettema EH, Girzalsky W, van den Berg M, Erdmann R, Distel B. 2000. Saccharomyces cerevisiae pex3p and pex $19 \mathrm{p}$ are required for proper localization and stability of peroxisomal membrane proteins. EMBO J 19: 223233.

Hoepfner D, Schildknegt D, Braakman I, Philippsen P, Tabak HF. 2005. Contribution of the endoplasmic reticulum to peroxisome formation. Cell 122: 85-95.

Höhfeld J, Veenhuis M, Kunau WH. 1991. PAS3, a Saccharomyces cerevisiae gene encoding a peroxisomal integral membrane protein essential for peroxisome biogenesis. J Cell Biol 114: 1167-1178.

Honsho M, Tamura S, Shimozawa N, Suzuki Y, Kondo N, Fujiki Y. 1998. Mutation in PEX16 is causal in the peroxisome-deficient Zellweger syndrome of complementation group D. Am J Hum Genet 63: 1622-1630. 
Hu C.-D, Chinenov Y, Kerppola TK. 2002. Visualization of interactions among bZIP and Rel family proteins in living cells using bimolecular fluorescence complementation. Mol Cell 9: 789-798.

Imanaka T, Shiina Y, Takano T, Hashimoto T, Osumi T. 1996 Insertion of the 70-kDa peroxisomal membrane protein into peroxisomal membranes in vivo and in vitro. J Biol Chem 271: 3706-3713.

Jones JM, Morrell JC, Gould SJ. 2004. PEX19 is a predominantly cytosolic chaperone and import receptor for class 1 peroxisomal membrane proteins. J Cell Biol 164: 57-67.

Kim PK, Mullen RT, Schumann U, Lippincott-Schwartz J. 2006. The origin and maintenance of mammalian peroxisomes involves a de novo PEX16-dependent pathway from the ER. J Cell Biol 173: 521-532.

Kragt A, Voorn-Brouwer T, van den Berg M, Distel B. 2005 Endoplasmic reticulum-directed Pex3p routes to peroxisomes and restores peroxisome formation in a Saccharomyces cerevisiae pex3Delta strain. J Biol Chem 280: 34350-34357.

Kunau WH. 1998. Peroxisome biogenesis: From yeast to man. Curr Opin Microbiol 1: 232-237.

Kunau WH, Erdmann R. 1998. Peroxisome biogenesis: Back to the endoplasmic reticulum? Curr Biol 8: R299-302.

Lam SK, Yoda N, Schekman R. 2010. A vesicle carrier that mediates peroxisome protein traffic from the endoplasmic reticulum. Proc Natl Acad Sci 107: 21523-21528.

Lazarow PB, Fujiki Y. 1985. Biogenesis of peroxisomes. Annu Rev Cell Biol 1: 489-530.

Liu H, Tan X, Veenhuis M, McCollum D, Cregg JM. 1992. An efficient screen for peroxisome-deficient mutants of Pichia pastoris. J Bacteriol 174: 4943-4951.

Matsuzaki T, Fujiki Y. 2008. The peroxisomal membrane protein import receptor Pex $3 p$ is directly transported to peroxisomes by a novel Pex19p- and Pex16p-dependent pathway. J Cell Biol 183: 1275-1286.

Motley AM, Hettema EH. 2007. Yeast peroxisomes multiply by growth and division. J Cell Biol 178: 399-410.

Neuspiel M, Schauss AC, Braschi E, Zunino R, Rippstein P, Rachubinski RA, Andrade-Navarro MA, McBride HM. 2008. Cargo-selected transport from the mitochondria to peroxisomes is mediated by vesicular carriers. Curr Biol 18: $102-108$.

Novikoff PM, Novikoff AB. 1972. Peroxisomes in absorptive cells of mammalian small intestine. J Cell Biol 53: 532560.

Osborne AR, Rapoport TA, van den Berg B. 2005. Protein translocation by the Sec61/SecY channel. Annu Rev Cell Dev Biol 21: 529-550.

Passreiter M, Anton M, Lay D, Frank R, Harter C, Wieland FT, Gorgas K, Just W. 1998. Peroxisome biogenesis: Involvement of ARF and coatomer. J Cell Biol 141: 373-383.

Raychaudhuri S, Prinz WA. 2008. Nonvesicular phospholipid transfer between peroxisomes and the endoplasmic reticulum. Proc Natl Acad Sci 105: 15785-15790.

Rottensteiner H, Kramer A, Lorenzen S, Stein K, Landgraf C, Volkmer-Engert R, Erdmann R. 2004. Peroxisomal membrane proteins contain common Pex19p-binding sites that are an integral part of their targeting signals. $\mathrm{Mol}$ Biol Cell 15: 3406-3417.
Rucktäschel R, Halbach A, Girzalsky W, Rottensteiner H, Erdmann R. 2010. De novo synthesis of peroxisomes upon mitochondrial targeting of Pex3p. Eur J Cell Biol 89: 947-954.

Sacksteder KA, Gould SJ. 2000. The genetics of peroxisome biogenesis. Annu Rev Genet 34: 623-652.

Sacksteder KA, Jones JM, South ST, Li X, Liu Y, Gould SJ. 2000. PEX19 binds multiple peroxisomal membrane proteins, is predominantly cytoplasmic, and is required for peroxisome membrane synthesis. J Cell Biol 148: 931944.

Salomons FA, van der Klei IJ, Kram AM, Harder W, Veenhuis M. 1997. Brefeldin A interferes with peroxisomal protein sorting in the yeast Hansenula polymorpha. FEBS Lett 411: 133-139.

Schliebs W, Girzalsky W, Erdmann R. 2010. Peroxisomal protein import and ERAD: Variations on a common theme. Nat Rev Mol Cell Biol 11: 885-890.

Schuldiner M, Metz J, Schmid V, Denic V, Rakwalska M, Schmitt HD, Schwappach B, Weissman JS. 2008. The GET complex mediates insertion of tail-anchored proteins into the ER membrane. Cell 134: 634-645.

Snyder WB, Koller A, Choy AJ, Subramani S. 2000. The peroxin Pex19p interacts with multiple, integral membrane proteins at the peroxisomal membrane. J Cell Biol 149: $1171-1178$.

South ST, Gould SJ. 1999. Peroxisome synthesis in the absence of preexisting peroxisomes. J Cell Biol 144: 255266.

South ST, Sacksteder KA, Li X, Liu Y, Gould SJ. 2000. Inhibitors of COPI and COPII do not block PEX3-mediated peroxisome synthesis. J Cell Biol 149: 1345-1360.

South ST, Baumgart E, Gould SJ. 2001. Inactivation of the endoplasmic reticulum protein translocation factor, Sec61p, or its homolog, Ssh1p, does not affect peroxisome biogenesis. Proc Natl Acad Sci 98: 12027-12031.

Steinberg SJ, Dodt G, Raymond GV, Braverman NE, Moser AB, Moser HW. 2006. Peroxisome biogenesis disorders. Biochim Biophys Acta 1763: 1733-1748.

Subramani S. 1998. Components involved in peroxisome import, biogenesis, proliferation, turnover, and movement. Physiol Rev 78: 171-188.

Swinkels BW, Gould SJ, Bodnar AG, Rachubinski RA, Subramani S. 1991. A novel, cleavable peroxisomal targeting signal at the amino-terminus of the rat 3-ketoacylCoA thiolase. EMBO J 10: 3255-3262.

Tabak HF, van der Zand A, Braakman I. 2008. Peroxisomes: Minted by the ER. Curr Opin Cell Biol 20: 393-400.

Tam YYC, Fagarasanu A, Fagarasanu M, Rachubinski RA. 2005. Pex3p initiates the formation of a preperoxisomal compartment from a subdomain of the endoplasmic reticulum in Saccharomyces cerevisiae. J Biol Chem 280: 34933-34939.

Tan X, Titorenko VI, van der Klei IJ, Sulter GJ, Haima P, Waterham HR, Eyers M, Harder W, Veenhuis M, Cregg JM. 1995. Characterization of peroxisome-deficient mutants of Hansenula polymorpha. Curr Genet 28: $248-257$.

Thoms S, Harms I, Kalies K-U, Gärtner J. 2012. Peroxisome formation requires the endoplasmic reticulum channel protein Sec61. Traffic 13: 599-609. 


\section{Dimitrov et al.}

Titorenko VI, Rachubinski RA. 1998. The endoplasmic reticulum plays an essential role in peroxisome biogenesis. Trends Biochem Sci 23: 231-233.

Titorenko VI, Rachubinski RA. 2000. Peroxisomal membrane fusion requires two AAA family ATPases, Pexlp and Pex6p. J Cell Biol 150: 881-886.

Titorenko VI, Chan H, Rachubinski RA. 2000. Fusion of small peroxisomal vesicles in vitro reconstructs an early step in the in vivo multistep peroxisome assembly pathway of Yarrowia lipolytica. J Cell Biol 148: 29-44.

van der Zand A, Braakman I, Tabak HF. 2010. Peroxisomal membrane proteins insert into the endoplasmic reticulum. Mol Biol Cell 21: 2057-2065.

van der Zand A, Gent J, Braakman I, Tabak HF. 2012. Biochemically distinct vesicles from the endoplasmic reticulum fuse to form peroxisomes. Cell 149: 397-409.
Voorn-Brouwer T, Kragt A, Tabak HF, Distel B. 2001. Peroxisomal membrane proteins are properly targeted to peroxisomes in the absence of COPI- and COPII-mediated vesicular transport. J Cell Sci 114: 2199-2204.

Yewdell JW. 2005. The seven dirty little secrets of major histocompatibility complex class I antigen processing. Immunol Rev 207: 8-18.

Yonekawa S, Furuno A, Baba T, Fujiki Y, Ogasawara Y, Yamamoto A, Tagaya M, Tani K. 2011. Sec16B is involved in the endoplasmic reticulum export of the peroxisomal membrane biogenesis factor peroxin 16 (Pex16) in mammalian cells. Proc Natl Acad Sci 108: 12746-12751.

Zanetti G, Pahuja KB, Studer S, Shim S, Schekman R. 2012. COPII and the regulation of protein sorting in mammals. Nat Cell Biol 14: 20-28. 


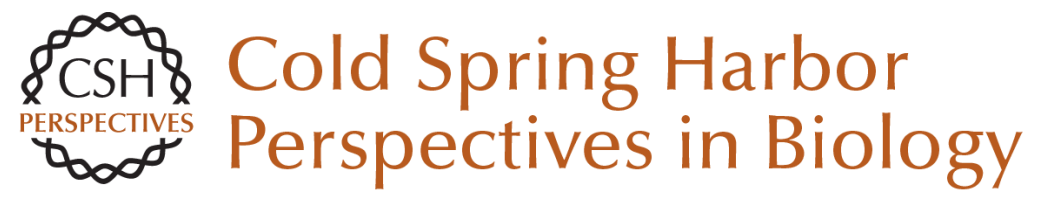

\section{The Role of the Endoplasmic Reticulum in Peroxisome Biogenesis}

Lazar Dimitrov, Sheung Kwan Lam and Randy Schekman

Cold Spring Harb Perspect Biol 2013; doi: 10.1101/cshperspect.a013243

Subject Collection The Endoplasmic Reticulum

Sorting and Export of Proteins at the Endoplasmic Reticulum

Ishier Raote, Sonashree Saxena and Vivek Malhotra

Endoplasmic Reticulum Membrane Contact Sites, Lipid Transport, and Neurodegeneration Andrés Guillén-Samander and Pietro De Camilli

AMPylation and Endoplasmic Reticulum Protein Folding Homeostasis

Luke A. Perera and David Ron

The Endoplasmic Reticulum and the Fidelity of Nascent Protein Localization

Michael J. McKenna and Sichen Shao

Endoplasmic Reticulum Architecture and Inter-Organelle Communication in Metabolic Health and Disease

Ana Paula Arruda and Günes Parlakgül

Regulation and Functions of the ER-Associated

Nrf1 Transcription Factor

Gary Ruvkun and Nicolas Lehrbach

Mechanism of Protein Translocation by the Sec61

Translocon Complex

Samuel Itskanov and Eunyong Park

Evolutionary Aspects of the Unfolded Protein

Response

Kazutoshi Mori
Glycerolipid Synthesis and Lipid Droplet

Formation in the Endoplasmic Reticulum

Robert V. Farese, Jr. and Tobias C. Walther

The Biogenesis of Multipass Membrane Proteins Luka Smalinskaite and Ramanujan S. Hegde

A TAle of Two Pathways: Tail-Anchored Protein Insertion at the Endoplasmic Reticulum Alina Guna, Masami Hazu, Giovani Pinton Tomaleri, et al.

Cholesterol Transport to the Endoplasmic

Reticulum John P. Kennelly and Peter Tontonoz

The Role of the Rhomboid Superfamily in ER

Protein Quality Control: From Mechanisms and

Functions to Diseases

Satarupa Bhaduri, Nicola A. Scott and Sonya E. Neal

ER-Phagy: Quality and Quantity Control of the

Endoplasmic Reticulum by Autophagy Haruka Chino and Noboru Mizushima

Structure and Function of the Nuclear Pore Complex

Stefan Petrovic, George W. Mobbs, Christopher J. Bley, et al.

Post-Translational Regulation of HMG CoA

Reductase

Youngah Jo and Russell A. DeBose-Boyd

For additional articles in this collection, see http://cshperspectives.cshlp.org/cgi/collection/

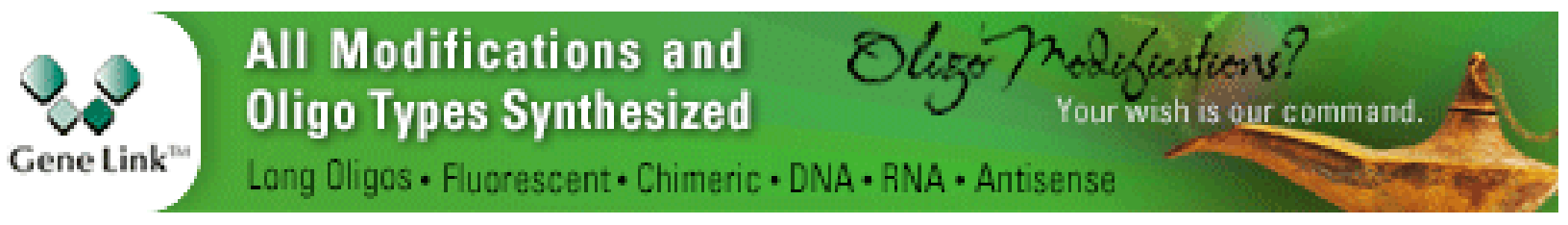


For additional articles in this collection, see http://cshperspectives.cshlp.org/cgi/collection/

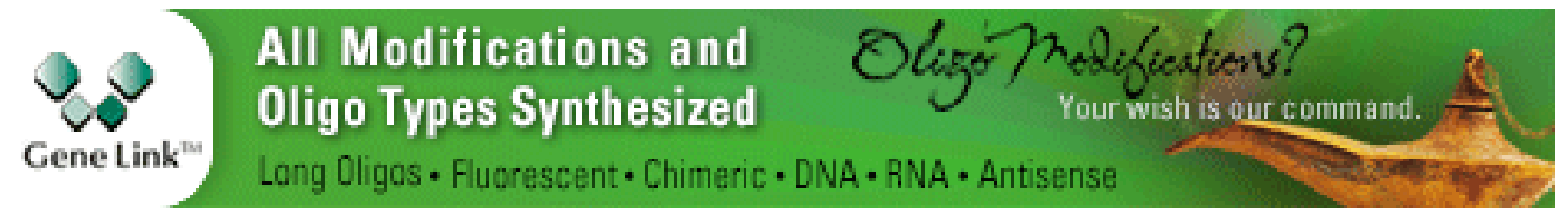

Copyright @ 2013 Cold Spring Harbor Laboratory Press; all rights reserved 